\title{
Present Status and Prospect of High-Frequency Electro-hydraulic Vibration Control Technology
}

\author{
Yi Liu'1,2,3 ${ }^{1}$, Tao Wang ${ }^{1}$, Guofang Gong ${ }^{2^{*}}$ and Rujun Gao ${ }^{1,2}$
}

\begin{abstract}
Electro-hydraulic vibration equipment (EHVE) is widely used in vibration environment simulation tests, such as vehicles, weapons, ships, aerospace, nuclear industries and seismic waves replication, etc., due to its large output power, displacement and thrust, as well as good workload adaptation and multi-controllable parameters. Based on the domestic and overseas development of high-frequency EHVE, dividing them into servo-valve controlled vibration equipment and rotary-valve controlled vibration equipment. The research status and progress of high-frequency electro-hydraulic vibration control technology (EHVCT) are discussed, from the perspective of vibration waveform control and vibration controller. The problems of current electro-hydraulic vibration system bandwidth and waveform distortion control, stability control, offset control and complex vibration waveform generation in high-frequency vibration conditions are pointed out. Combining the existing rotary-valve controlled high-frequency electro-hydraulic vibration method, a new twin-valve independently controlled high-frequency electro-hydraulic vibration method is proposed to break through the limitations of current electro-hydraulic vibration technology in terms of system frequency bandwidth and waveform distortion. The new method can realize independent adjustment and control of vibration waveform frequency, amplitude and offset under high-frequency vibration conditions, and provide a new idea for accurate simulation of high-frequency vibration waveform.
\end{abstract}

Keywords: Electro-hydraulic vibration equipment, High-frequency, Vibration control, Vibration waveform, Twin-valve

\section{Introduction}

Vibration equipment mainly refers to a kind of equipment to generate the corresponding vibration by mechanical, electro-dynamic, electrostrictive or magnetostrictive, electro-hydraulic and other driving principles with the form of shaking table and vibration exciter. Among them, electro-hydraulic vibration equipment (EHVE) is widely used in vibration environment simulation tests, such as vehicles, weapons, ships, aerospace, nuclear industries and seismic waves replication, etc. [1-4], has large output power, displacement and thrust, adaptive workload and multi-controllable parameters. With the further study of high-frequency EHVE, the vibration frequency has been

\footnotetext{
*Correspondence: gfgong@zju.edu.cn

2 State Key Laboratory of Fluid Power Transmission and Control, Zhejiang University, Hangzhou 310027, China

Full list of author information is available at the end of the article
}

improved greatly in recent years. But due to the limitations of system bandwidth and influence of nonlinearity, the traditional electro-hydraulic vibration control technology (EHVCT) based on servo control has a deviation between the response signal and expected input signal, the current vibration control requirements of highaccuracy, low-distortion and high-stability are difficult to meet. Therefore, developing a high-frequency EHVCT which can accurately control the EHVE and make the vibration waveforms to meet the above-mentioned vibration control requirements is the key to improve the existing vibration environment simulation testing technology.

This paper describes the domestic and overseas development of high-frequency EHVE, discusses the research status of high-frequency EHVCT, points out the existing problems of current high-frequency EHVCT, and discusses the solutions to some problems. 


\section{Development of High-Frequency Electro-hydraulic Vibration Equipment}

The main excitation forms of vibration equipment at present are mechanical excitation, electro-dynamic excitation and electro-hydraulic excitation. Compared with the other two forms, electro-hydraulic excitation has been widely used due to its unique advantages. With the development of related technology and improvement of testing requirement, promoting the EHVE to develop from medium-frequency and low-frequency to high-frequency and from low-precision to high-precision vibration control. Then according to the types of vibration control element, the EHVE is mainly divided into servo-valve controlled vibration equipment and rotary-valve controlled vibration equipment.

\subsection{Servo-valve Controlled Vibration Equipment}

Overseas research on high-frequency servo-valve controlled vibration equipment is more early, various vibration environment simulation testing devices composed of electro-hydraulic shaking table (EHST) have been developed and the most products have been series manufactured, formed a certain market scale and industry. The EHST is mainly composed of electro-hydraulic actuators controlled by electro-hydraulic servo-valve. The working principle is that processing the desired signal of the user by a certain algorithm to generate the electronic control driving signal firstly, and then converting it into current signal by an amplifier to excite the electrohydraulic servo-valve secondly. Finally, the hydraulic oil proportional to the driving signal is input to the hydraulic cylinder to drive the piston rod to generate the desired vibration simulation environment. However, due to the limitations of frequency response ability of servo-valve, the working frequency of EHST is usually lower and suitable only for the medium-frequency and low-frequency vibration environment simulation. In order to improve the high-frequency performance of EHST, one of the ways is to introduce a servo-valve with high-frequencyresponse. At present, the overseas advanced high-frequency-response servo-valve manufacturers are mainly represented by MTS and MOOG in American, while the EHST manufacturers are mainly represented by TEAM in American, SERVOTEST in Britain, and IMV in Japan.

As shown in Figure 1 [5], the high-performance voice coil servo-valve is developed by MTS company for highcycle fatigue testing machine. The frequency response can reach more than $1000 \mathrm{~Hz}$, and has high control accuracy and low waveform distortion in high-frequency conditions. As shown in Figure 2 [6], the 256 series high-performance electro-hydraulic 3-stage servo-valve is developed by MTS company. The rated flow rate can

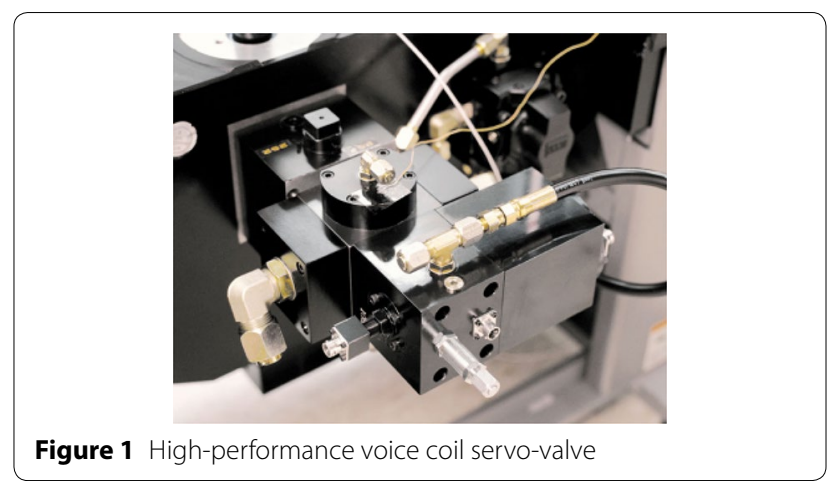

Figure 1 High-performance voice coil servo-valve

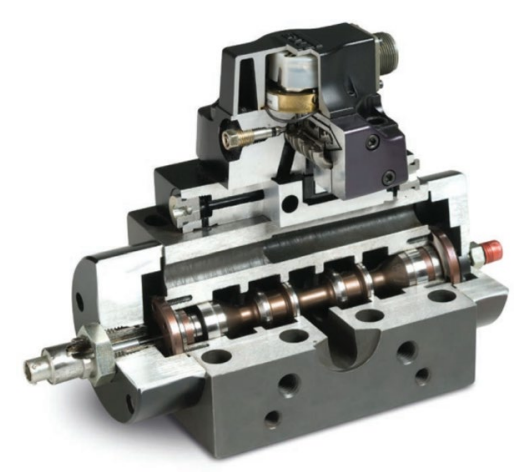

Figure 2 Electro-hydraulic 3-stage servo-valve

reach $1500 \mathrm{~L} / \mathrm{min}$ and working frequency can reach more than $100 \mathrm{~Hz}$. Thus, MTS has been in the monopoly position in some special applications of electro-hydraulic servo testing machine. Besides, as the largest manufacturer of servo-valve in the world, MOOG has developed series of high-performance servo-valves [7], and the performance parameters of different series are show in Table 1 [8-11].

As the earliest developer of 6 degree-of-freedom (DOF) vibration system in the world, TEAM produces singleaxis and multi-axis electro-hydraulic shaking tables. The maximum working frequency up to $1000 \mathrm{~Hz}$, and has a high waveform replication accuracy due to its unique hydraulic system design, high machining accuracy and high-speed self-adaptation real-time controller. Such as the MANTIS 6-DOF EHST is shown in Figure 3 [12], its frequency range is $0-200 \mathrm{~Hz}$, maximum excitation force can reach $150 \mathrm{kN}$ and maximum working stroke can reach $150 \mathrm{~mm}$; the CUBE 6-DOF EHST is shown in Figure 4 [13], its frequency range is $0-500 \mathrm{~Hz}$, maximum excitation force can reach $90 \mathrm{kN}$ and maximum working stroke can reach $100 \mathrm{~mm}$. The first engine simulation system in the world launched by TEAM is shown in Figure 5 [14]. Through its core component torsion actuator and electro-hydraulic servo motor, the output torque curves 
Table 1 The performance parameters of different series of MOOG servo-valve

\begin{tabular}{lllll}
\hline Series & Frequency response $\mathbf{( H z )}$ & Step response (ms) & Flow range (L/min) & $\begin{array}{l}\text { Maximum } \\
\text { working } \\
\text { pressure (MPa) }\end{array}$ \\
\hline D633/634 & $20-70$ & $12-15$ & $3.8-100$ & 31.5 \\
D765 & $90-250$ & $2-4$ & $3.8-63$ & 35 \\
760 & $70-250$ & $4-15$ & $3.8-63$ & 35 \\
79 & $60-90$ & $6-15$ & $114-760$ & 35 \\
\hline
\end{tabular}

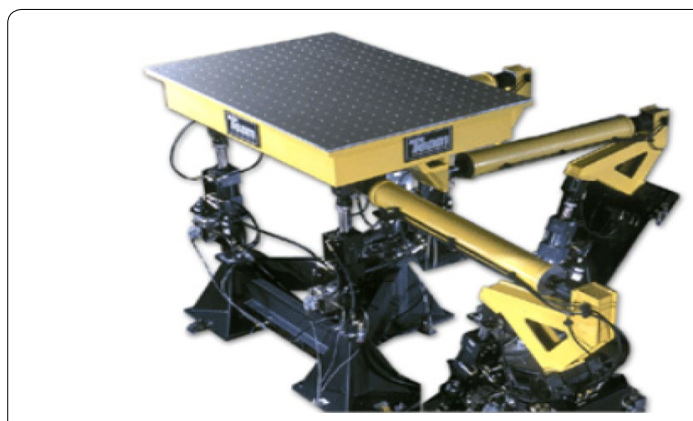

Figure 3 MANTIS 6-DOF electro-hydraulic shaking table

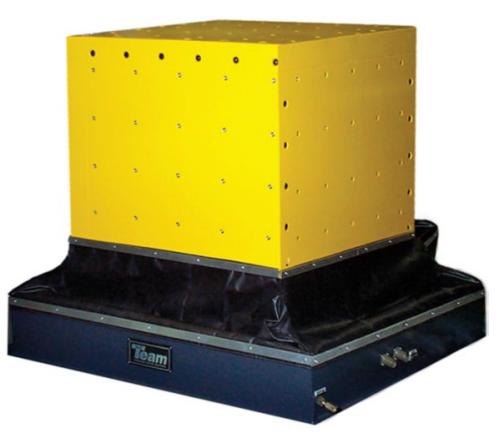

Figure 4 CUBE 6-DOF electro-hydraulic shaking table

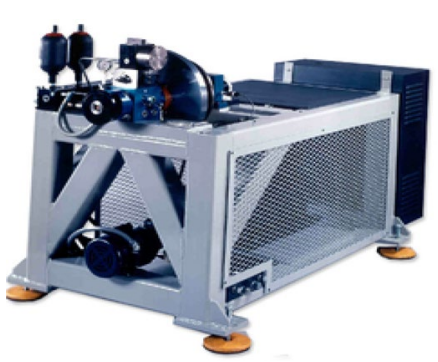

Figure $\mathbf{5}$ TEAM engine simulation system

of the engine can be accurately simulated to provide support for the design of the whole engine and auxiliary system. Such as the rotary speed of model 901 engine

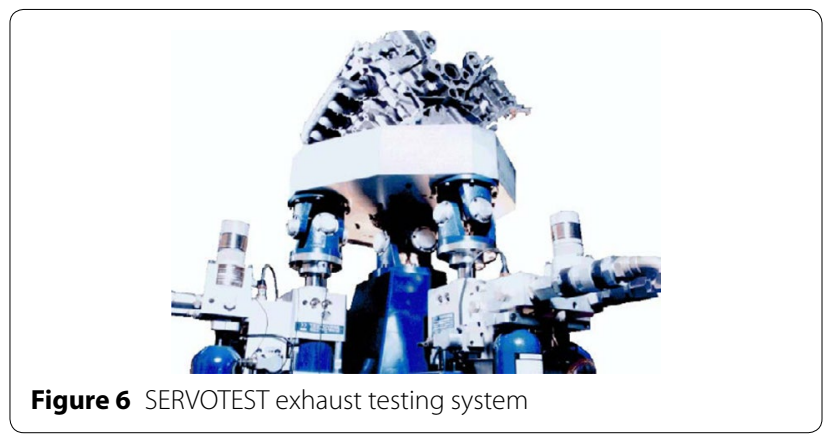

simulation system can reach $10000 \mathrm{r} / \mathrm{min}$, the output torque can reach $3600 \mathrm{~N} \cdot \mathrm{m}$, and the torsional vibration frequency can reach $600 \mathrm{~Hz}$; the torque of model R10 electro-hydraulic servo torsion actuator using hydrostatic bearing design for fatigue vibration tests of materials and structures can reach over $20 \mathrm{kN} \cdot \mathrm{m}$, the dynamic swing angle can reach $\pm 50^{\circ}$ and the working frequency can reach over $500 \mathrm{~Hz}$.

SERVOTEST is one of the earliest companies engaged in multi-axis EHST research, and leading in servo hydraulic testing and motion simulation industry. The table size range of the EHST produced by SERVOTEST is $0.5 \mathrm{~m} \times 0.5 \mathrm{~m}-6 \mathrm{~m} \times 6 \mathrm{~m}$, the frequency range is $0.1-200 \mathrm{~Hz}$, the vertical ultimate bearing capacity is $1000 \mathrm{kN}$, and the horizontal direction is $600 \mathrm{kN} \mathrm{[15].} \mathrm{The}$ exhaust testing system is shown in Figure 6 [16], can simulate the high-frequency vibration environment of the engine and provide support for the structural design of engine manifold. The seismic simulation system is shown in Figure 7 [17], has an advanced digital control system and high-performance actuator, can accurately reproduce the actual seismic environment.

Japan is one of the earliest countries to develop hydraulic vibration testing system, and occupies a certain leading edge in technology. Such as the vehicle seat comfort assessment system is shown in Figure 8 [18], developed by IMV company in Japan for comfort assessment of vehicle seats. Its maximum working stroke can reach $150 \mathrm{~mm}$, the maximum working frequency is more than $100 \mathrm{~Hz}$, and the maximum 


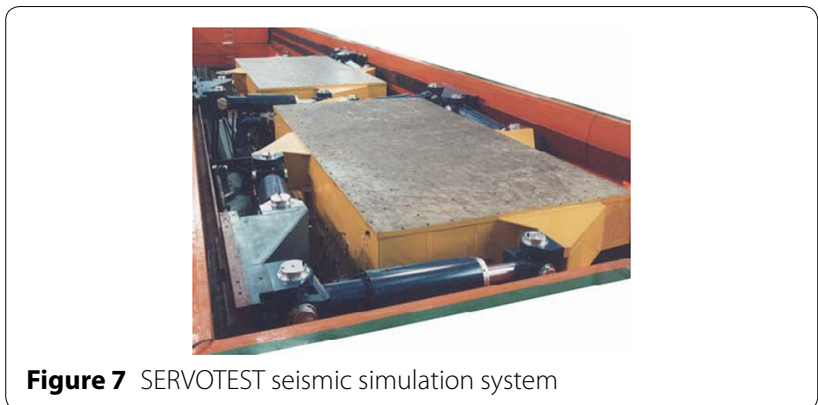

Figure 7 SERVOTEST seismic simulation system

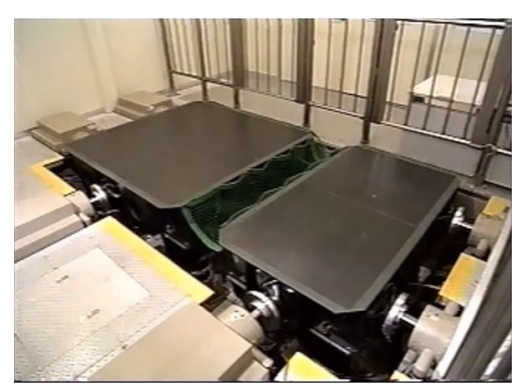

Figure $8 \mathrm{IMV}$ vehicle seat comfort assessment system

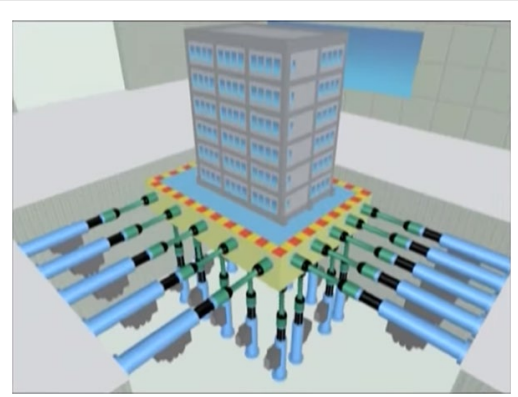

Figure 9 E-DEFENSE seismic simulation testing system

excitation force is more than $16 \mathrm{kN}$. The world's largest 3-D full-scale seismic simulation testing system E-DEFENSE is shown in Figure 9 [19], built by National Research Institute for Earth Science and Disaster Prevention in Japan. The horizontal displacement is 1000 $\mathrm{mm}$, horizontal velocity is $2000 \mathrm{~mm} / \mathrm{s}$, and horizontal acceleration is $0.9 g$; the vertical displacement is $500 \mathrm{~mm}$, vertical velocity is $700 \mathrm{~mm} / \mathrm{s}$, and vertical acceleration is $1.5 \mathrm{~g}$. So it can test the real-sized house structure in a complex 3-D motion environment, and provides strong support for the research and development of anti-seismic technology of Japan.

In addition, there are many companies have also successfully developed various high-frequency electrohydraulic vibration equipment, such as WYLE and IST

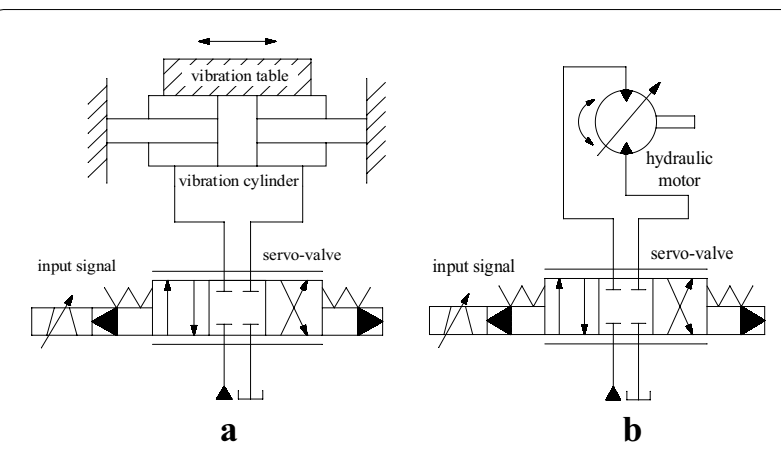

Figure 10 Scheme of electro-hydraulic excitation: a valve controlled cylinder vibration system, $\mathbf{b}$ valve controlled motor vibration system

company in American, REXROTH and SCHENCH company in Germany, INSTRON company in British, AMSLER company in Switzerland, Mitsubishi and Saginomiya company in Japan. However, due to the impact of embargo, high-price and power restrictions, etc., these equipments have rarely been popularized and applied in China.

By contrast, the research on high-frequency EHVE in China started relatively late, especially in the research and manufacture of large-scale vibration simulation testing equipments. Compared with the overseas advanced level, there is a big gap in both technical and scale in China. The achievements [20-23] obtained in recent years based on technology introduction and independent research cannot be ignored, but the mature and reliable products are relatively less, and mainly distributed in universities and research institutes.

\subsection{Rotary-valve Controlled Vibration Equipment}

From the research above-mentioned, it can be seen that the current commonly used electro-hydraulic excitation scheme is mainly composed of an electro-hydraulic actuator (hydraulic cylinder or hydraulic motor) controlled by electro-hydraulic servo-valve, as shown in (a) and (b) of Figure 10. The vibration frequency is difficult to rise to a higher level due to the limitations of frequency response characteristics of servo-valve and excitation principle of spool reciprocating motion. And due to the influence of resonance and system nonlinearity caused by pump pressure fluctuation and oil compressibility, etc. under high-frequency excitation conditions, the distortion of vibration waveforms is serious, thus, the vibration frequency can only be limited to a lower range about $0-100 \mathrm{~Hz}$. As a result, most of the domestic high-frequency electro-hydraulic servo vibration systems above $100 \mathrm{~Hz}$ are imported from overseas. The rotary-valve can realize opening and closing of oil circuit and flow control by the rotation of spool (or sleeve) relative to the valve 
body. Compared with the linear-valve, the rotary-valve is easy to realize high-frequency excitation and micro-flow control with high-resolution. The movement of the spool has no acceleration zero drift with high control accuracy, and directly driven by a servo motor or stepping motor with a compact and simple structure. Just because of the above advantages of rotary-valve, in recent years, the rotary-valve controlled vibration equipment has developed rapidly and become a research hotspot in the field of high-frequency electro-hydraulic vibration technology.

Domestic and overseas scholars try to improve the performance of EHVE by designing and optimizing the structure of new rotary-valves, and break through the limitations of spool reciprocating excitation to meet the requirements of high-frequency excitation. The high-frequency rotary-valve is shown in Figure 11, designed by Goldfarb et al. [24] from Vanderbilt University. The spool can be driven by a servo motor to rotate freely and the working frequency determined by the servo motor rotary speed. The working principle is that with the rotation of spool, oil flows through the groove on spool and then the oil port $\mathrm{P}$ and oil port A are connected, simultaneously, as well as the oil port B and oil port T. Similarly, as the spool rotates to a certain angle, the oil port $\mathrm{P}$ and the oil port B are connected, simultaneously, as well as the oil port $\mathrm{A}$ and oil port $\mathrm{T}$. Based on the above principles, high-frequency excitation can be realized with the rotation of spool.

The pilot rotary-spool driven electro-hydraulic directional control valve is shown in Figure 12, invented by Kerckhove et al. [25] from Caterpillar Company. The pilot rotary-spool is equipped with spiral grooves consisted of high-pressure grooves and low-pressure grooves. The high-pressure grooves are connected with the oil supply port and the low-pressure grooves are connected with the oil return port. As the pilot rotary-spool rotates to a certain angle, the radial symmetry circular window on valve sleeve and the spiral groove on pilot rotary-spool

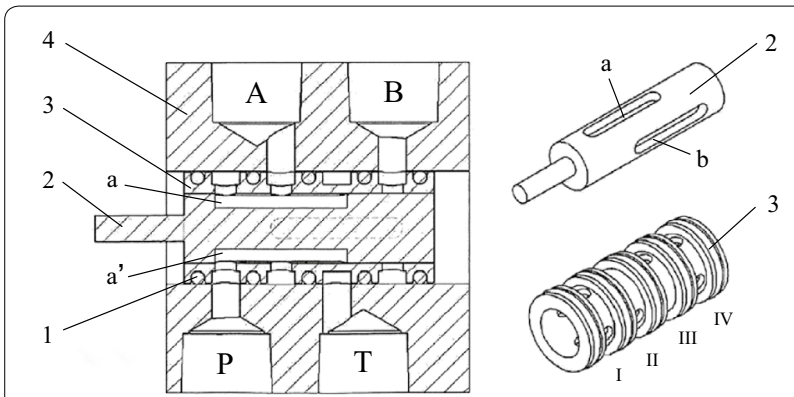

Figure 11 High-frequency rotary-valve. 1. O ring; 2. Spool; 3. Valve sleeve, 4. Valve body

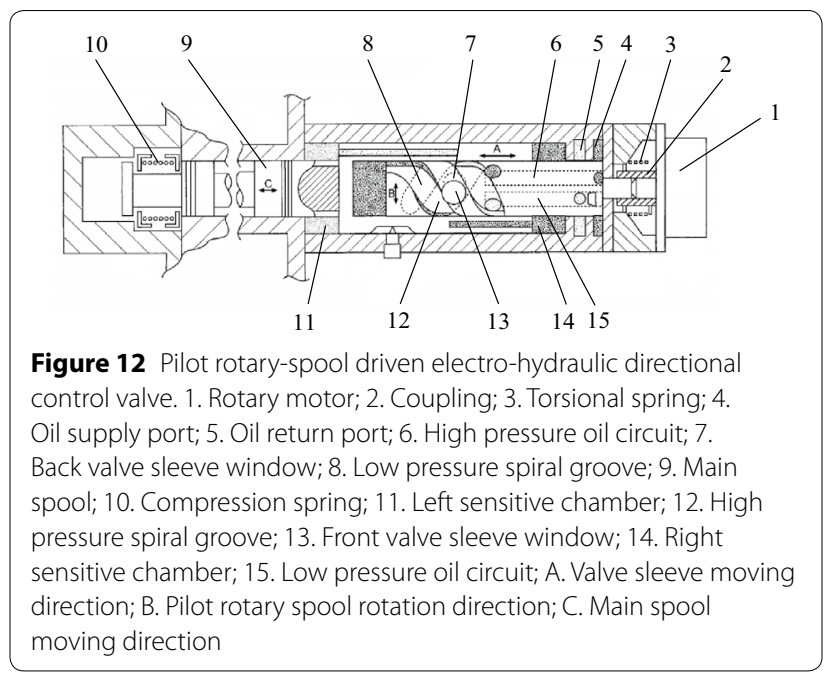

overlap each other, which makes the oil from the spiral groove on pilot rotary-spool flow through the circular window on valve sleeve into the two sensitive chambers of the valve. Because of the structure characteristic of the spiral groove on pilot rotary-spool driven by a rotary motor, the overlapping area of the high-pressure spiral groove and circular window on valve sleeve is different from the overlapping area of the low-pressure spiral groove and circular window on valve sleeve. So existing a certain pressure difference between the left and right sensitive chambers of the valve, and then pushing the valve sleeve to move axially. And due to the rigid connection between the valve sleeve and main spool of the valve, the main spool moves axially to realize high-speed reversing and flow control of the electro-hydraulic directional control valve.

The 2-DOF fault tolerant electro-hydraulic directional control valve is shown in Figure 13, proposed by Italian scholar Ruggeri et al. [26]. The main characteristic is that the spool and valve sleeve is driven by a linear motor and a rotary motor respectively. The motion direction of the

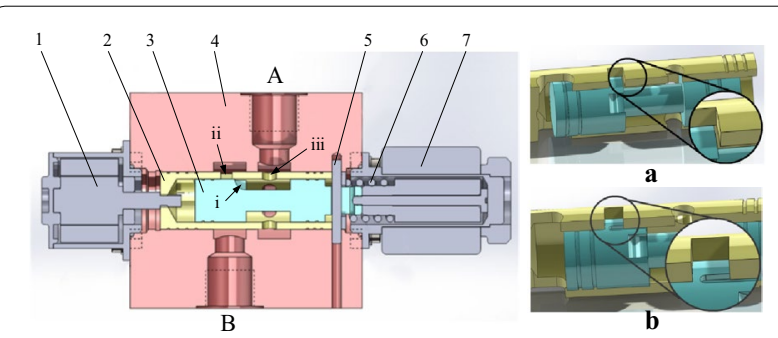

Figure 13 2-DOF fault tolerant electro-hydraulic directional control valve: $\mathbf{a}$ rotary failure state of valve sleeve; $\mathbf{b}$ movement failure state of spool. 1. Rotary motor; 2. Valve sleeve; 3 . Spool; 4 . Valve body; 5 . Pin; 6. Compression spring; 7 . Linear motor; i. Valve groove; ii, iii. Valve sleeve window 
spool is axial, while the motion direction of the valve sleeve is radial, and the rotation freedom of spool is limited by a pin. So that the independence movement of spool and valve sleeve can be realized. And it is because of the independence movement of spool and valve sleeve, on the one hand, the valve has a fault-tolerant characteristic, that is, the valve can still work normally while one of the degrees of freedom motion fails, which also expands its application range [27]. On the other hand, it can increase the response speed, working frequency and functional diversity. Through the coupling control of the linear motor and the rotary motor, the spool and valve sleeve will be in the preset position. And the grooves on spool and windows on valve sleeve will form a flowthrough valve port with a preset size. So that the proportional oil can flow through to realize the high-speed on-off and reversing of oil circuit and accurate flow control of the valve.

The 2-DOF high-speed on-off valve is shown in Figure 14, designed by Li et al. [28] from the University of Minnesota. The flow rate can be controlled by PWM signal. While the rated flow is $40 \mathrm{~L} / \mathrm{min}$, the PWM frequency can reach $84 \mathrm{~Hz}$, which is about $400 \%$ higher than that of the linear on-off valve. Based on a unidirectional rotary-spool and the spiral grooves on the surface of the spool can realize the on-off of the valve oil circuit. And the working frequency depends on the spool rotary speed, so it is easy to realize high-frequency excitation. While changing the axial displacement of the spool can control the duty cycle to realize accurate flow regulation of the valve. Subsequently, Wang [29] uses computational
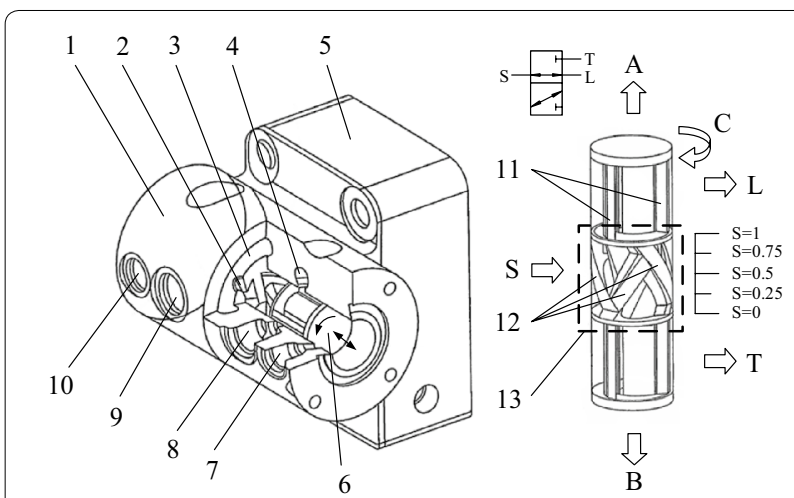

Figure 14 2-DOF high-speed on-off valve. 1. Valve sleeve; 2. Oil supply port; 3 . Inlet annular passage; 4 . Outlet annular passage; 5 . Pump case (integrated with valve sleeve); 6 . Rotary spool; 7 . Right spool displacement control outlet; 8 . Oil return port; 9. Load port; 10. Left spool displacement control outlet; 11 . Outlet turbine blade; 12. Inlet turbine blade; 13. PWM control area; A: Oil return flow increasing direction; B: Load flow increasing direction; C: Spool rotary direction; $\mathrm{S}$ : Flow direction of supply oil; L: Flow direction of load flow; T: Flow direction of return oil fluid dynamics (CFD) to analyze the flow field inside the valve and improves its structural design. By contrast, throttling loss of the valve is reduced by $62.5 \%$, hydraulic shrinkage loss is reduced by $66 \%$, and its efficiency is further improved.

The new 4-way high-speed rotary-valve is shown in Figure 15, designed by Pan et al. [30] from University of Bath-based on the previous research. By contrast, the valve has lower liquid resistance and flow leakage under high-flow workload conditions. The rotor is driven by a brushless servo motor with the maximum speed up to $5100 \mathrm{r} / \mathrm{min}$, and the working frequency is determined by the rotary speed. The working principle is that the oil flows from high-pressure oil port P to oil port B through the stator groove, rotor groove and control shaft groove in turn, that is, the oil port $\mathrm{P}$ and oil port $\mathrm{B}$ are connected; and while the oil flows from the oil port A through the stator groove, rotor groove and control shaft groove to low-pressure oil port $\mathrm{T}$ in turn, that is, the oil port $\mathrm{A}$ and oil port $\mathrm{T}$ are connected. When the rotor rotates to a certain angle, the oil circuit is reversed, making the oil port $\mathrm{P}$ and oil port $\mathrm{A}$ connected while the oil port $\mathrm{B}$ and oil port $\mathrm{T}$ connected. In this way, high-frequency reversing can be realized with the rotation of rotor. And the overlapping area of flow-through valve port can be changed by adjusting the angle position of control shaft, so that the flow rate of the valve can be accurately controlled.

Moreover, domestic scholars have also obtained many achievements in the research of rotary-valve controlled vibration equipment. Such as the 2D-valve controlled high-frequency EHVE is shown in Figure 16, proposed by Ruan et al. [31] from Zhejiang University of Technology for improving its working frequency. The spool has 2-DOF of motion, and the open-plus-closed-loop control of vibration frequency and amplitude can be realized by the coupling control of radial and axial movement of the

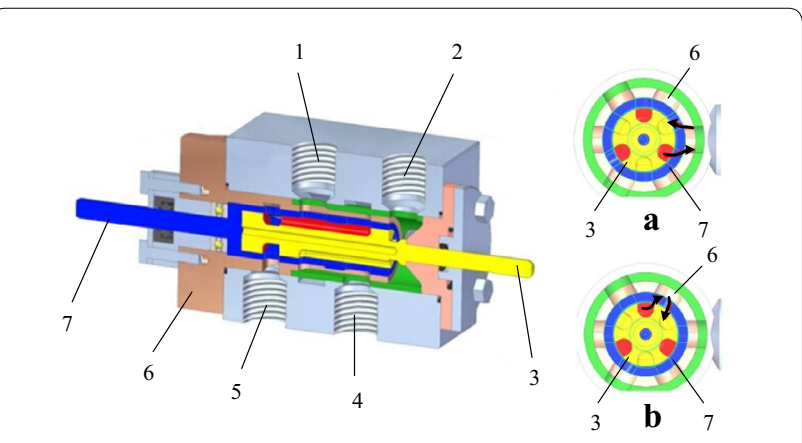

Figure 15 New type of 4-way high-speed rotary-valve: a leakage from rotor to stator; $\mathbf{b}$ leakage from control shaft to rotor. 1. Oil port B; 2. Low pressure oil port; 3. Control shaft; 4. Oil port A; 5. High pressure oil port; 6. Stator; 7. Rotor 


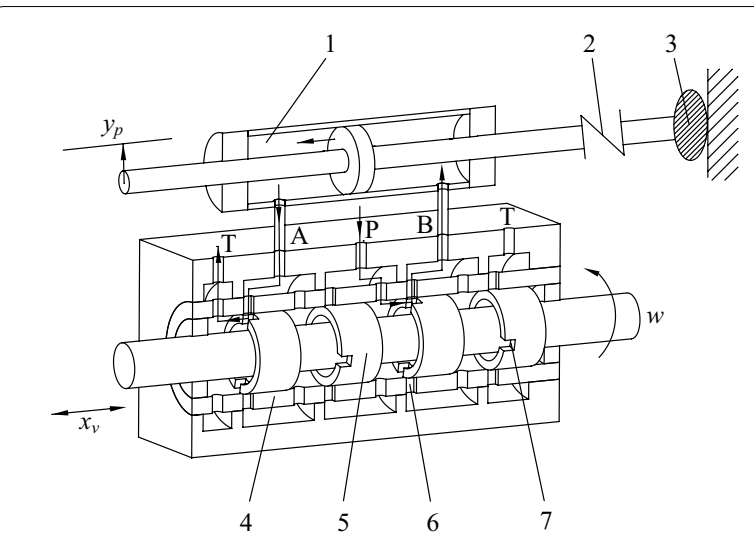

Figure 16 2D-valve controlled high-frequency electro-hydraulic vibration equipment. 1. Hydraulic cylinder; 2. Load sensor; 3. Load object; 4. Valve sleeve; 5. Spool; 6. Valve sleeve window; 7. Spool shoulder groove

spool. The main advantage is that the spool of the valve is always in a good lubrication environment, so it is easy to improve the vibration frequency by increasing the rotary speed of spool. Subsequently, Lu et al. [32] proved that the vibration frequency can exceed $2000 \mathrm{~Hz}$ while 16 grooves of spool shoulder and corresponding 16 windows of valve sleeve are alternately connected.

Gong et al. [33] from Zhejiang University inspired by the above-mentioned 2D-valve structure, invented an EHVE based on a single-shoulder rotary-spool, as shown in Figure 17. The working principle is that the valve port is alternately connected to realize high-frequency reversing through the rotation of spool driven by a stepping motor. And owing to the single-shoulder rotary-spool structure design, the high-frequency performance is better, structure size is smaller, the process is relatively simpler and the cost is lower. Besides, because of the integrated design of valve and hydraulic cylinder, the length of the hydraulic pipeline is shortened, pressure loss along the way is effectively reduced, and working efficiency is improved.

Furthermore, Han et al. [34] from Zhejiang University designed a new type of EHVE for the tamping device with independent hydraulic excitation and clamping, as shown in Figure 18, which consists of a four-way rotaryvalve and a micro-stroke double-rod hydraulic cylinder. Considering the influence of pressure drop on the valve port flow area, the corresponding flow area models of non-annular groove and annular groove are established respectively. Finally, the theoretical numerical simulation and experimental verification research on vibration waveforms of the new proposed EHVE under higher frequency are carried out.

\subsection{Other High-Frequency Vibration Equipment}

In addition to the above-mentioned electro-hydraulic actuator with high-frequency-response control valve, $\mathrm{Li}$ et al. [35] from Changchun Institute of Optics, Fine Mechanics and Physics provided a new idea and proposed a new EHVE driven by high-frequency magnetostrictive pump, as shown in Figure 19. The traditional pump driven circuit is replaced by a magnetostrictive driven pump, and the traditional 3-position 4-way solenoid valve is replaced by the two 2-position 3-way

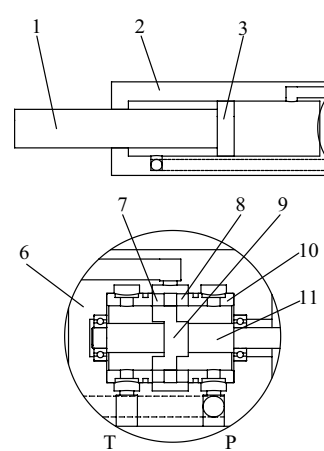

a
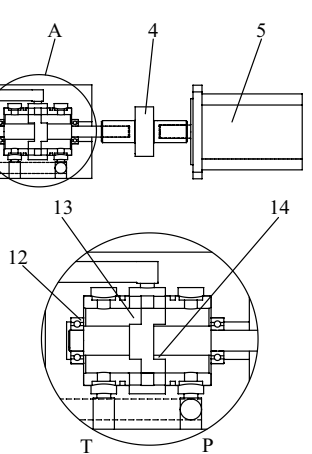

b

Figure 17 New type of electro-hydraulic vibration equipment with single shoulder spool: a left motion state of the hydraulic cylinder; $\mathbf{b}$ right motion state of the hydraulic cylinder. 1. Piston rod; 2 . Housing; 3. Piston; 4. Coupling; 5. Step motor; 6. Baffle; 7. First valve sleeve window; 8 . Second valve sleeve window; 9 . Shoulder; 10 . Valve sleeve; 11. Single shoulder spool; 12. Bearing; 13. First groove; 14. Second groove; A: Local structure; P: Oil supply port; T: Oil return port

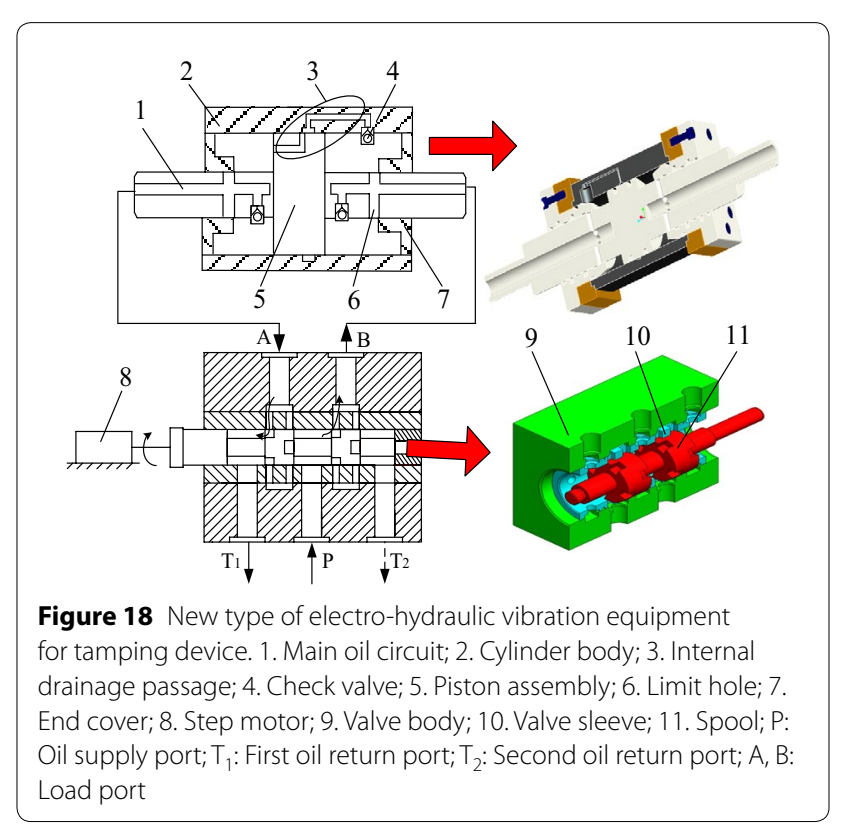




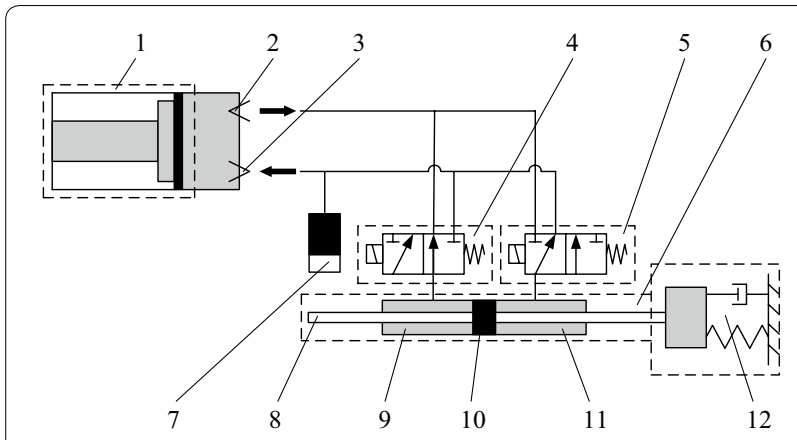

Figure 19 New type of electro-hydraulic vibration equipment driven by magnetostrictive driven pump. 1. Magnetostrictive drive pump; 2. First check valve; 3 . Second check valve; 4 . First directional control valve; 5 . Second directional control valve; 6 . Double rod hydraulic cylinder; 7. Accumulator; 8. Piston rod; 9. Left oil chamber; 10. Piston; 11. Right oil chamber; 12. Excited body

directional control valve driven by high-frequency piezoelectric ceramics. As a result, the double-rod hydraulic cylinder can realize high-frequency excitation, which is about several hundred hertz, and the vibration frequency of EHVE and cycle frequency of the oil circuit are greatly improved. Meanwhile, in the field of high-frequency vibration compaction, in order to improve the working efficiency of the vibration compaction device, Toet et al. [36] invented an electro-hydraulic vibration compaction device and proposed an operation method for it; in the field of high-frequency vibration piling, Kleibl et al. [37] invented a vibration device for vibration pile driver and simplified its structure; in the field of vibration control, Kobayashi et al. [38] provided a vibration device, which can prevent the vibration part from transverse dislocation to ensure the stability of the vibration process.

\section{Progress of High-Frequency Electro-hydraulic Vibration Control Technology}

\subsection{Progress of Vibration Waveform Control}

Vibration waveform control research has important practical significance for the development of high-frequency EHVE and EHVCT. Therefore, domestic and overseas scholars have conducted a lot of research on the vibration waveform replication accuracy and distortion of EHVE.

The three dominate parameters of the vibration waveform control of EHVE are displacement, velocity and acceleration, and change with the change of the frequency. In the early displacement control strategy, the low-frequency displacement signal is stronger and the feedback is enough, but the high-frequency signal is weaker, which is equivalent to the open-loop control. The three-parameter control is that the displacement, velocity and acceleration are all involved in the feedback control, which can provide feedback in the whole frequency bandwidth. As the high-frequency phase lag becomes larger and larger, the high-frequency acceleration cannot achieve as good a follow-up effect as the low-frequency displacement feedback. But generally, it is much better than the displacement control. Besides, an important difference between the three-parameter control and traditional displacement control is that the input is acceleration waveform. And a flat acceleration transfer function and a good control effect of acceleration waveform can be obtained while the parameters are appropriate.

In order to accurately simulate the reference acceleration signal, the three-parameter control technology [39, $40]$ is used to correct the dynamic characteristics of servo control system for improving the frequency response performance of servo system. But still cannot accurately reproduce the expected acceleration signal under highfrequency excitation conditions. The waveform replication accuracy can be further improved by using inverse transfer function equalization technology. Furthermore, the expected signal can be accurately reproduced in a wider frequency bandwidth by using feed forward compensation technology based on the inverse transfer function, which can improve the dynamic response performance of testing system, rather than changing the closed-loop feedback characteristic. So that, as long as the transfer function of the acceleration closed-loop control system is accurately identified and its inverse transfer function is designed, the dynamic characteristics of acceleration can be effectively compensated while the desired acceleration signal can be accurately reproduced through the acceleration closed-loop control system [15].

However, the EHST servo system has non-linear timevarying characteristic in testing and the acceleration closed-loop system may be affected by non-linear factors. On the one hand, leading to a model deviation between the designed inverse transfer function model and the actual system model, on the other hand, leading to a certain amplitude attenuation and phase delay of acceleration waveform, that is, waveform distortion, which will reduce the waveform control performance and even increase the instability of system. Therefore, it is necessary to consider the non-linearity and interference factors of electro-hydraulic servo system while establishing the mathematical model of EHST servo system. Such as Righettini et al. [41] established a non-linear empirical model of single-axis EHST. Kim et al. [42] proposed an output feedback non-linear control method for position tracking of electro-hydraulic vibration system. Wang et al. [43] considered the factors of uncertainties, nonlinearity and time-varying, established a model of parallel driven EHST servo system. Nakata [44] established a dynamic model of electro-hydraulic single-axis driven seismic simulator. Klimchik et al. [45] considered the 
influence of internal force and external interference force of parallel mechanism, established a stiffness model of parallel mechanism. Wei et al. [46] established a hydraulic system non-linear model of super-redundant EHST and a dynamic coupling model based on space forces. Shen et al. [47] established a hydraulic system non-linear model of parallel driven 6-DOF EHST. Yao et al. [48] developed a heuristic algorithm called water cycle algorithm (WCA), which can be used to identify the amplitude and phase of harmonic signals. Bruyne et al. [49] proposed a multi-axis EHST decoupling vibration control system, which can improve the performance of reference tracking, harmonic distortion and anti-crosstalk. Rana [50] introduced an intelligent time domain digital acceleration amplitude controller based on fuzzy logic for the sinusoidal vibration testing in the field of aerospace and automobile, which has a good reference tracking performance. Stehman et al. [51] proposed a new EHST control strategy, which is characterized by using acceleration feedback directly without displacement feedback. Besides, the force feedback is added to ensure the stability of EHST and reduce the drift of the table. As a result, the acceleration tracking performance and waveform accuracy are improved. Besides, Shen et al. [52] introduced other control algorithms of EHST servo system in the review for improving the replication accuracy of acceleration waveforms.

In addition to the above algorithms, the self-adaption control algorithm and off-line iterative control algorithm are the two most widely used control strategies in the field of EHST control, but both of them have their own advantages and disadvantages. Among them, once the self-adaption algorithm converges to an optimal solution, it can reproduce the reference time-domain waveform accurately. However, many self-adaption algorithms have the problem of slow convergence speed, which makes the self-adaption algorithm unable to be applied well to the EHST control. Meanwhile, the off-line iterative control is the most practical method to realize the waveform reproducing and the most commonly used method in industrial applications. But it may cause the divergence of the algorithm or more iterations when the dynamic characteristics of the sample are changed. Therefore, some scholars put forward various hybrid control strategies to overcome the problem of slow convergence speed of selfadaption control and off-line iterative control [15]. Such as Zhang et al. [53] proposed a hybrid control strategy to improve the synchronization and tracking control accuracy of double EHST system. Compared with the traditional control strategy, the tracking error can be reduced to $25 \%$ and the synchronization error to $16 \%$. Tang et al. [54] proposed a combined control strategy combining off-line iterative learning control and improved internal model control to improve the time domain waveform replication accuracy of EHST. Yan et al. [55] aimed at the problem of poor control effect of electro-hydraulic vibration system under high-frequency, proposed a hybrid control strategy combining displacement control and acceleration control. The displacement control is mainly used in low-frequency and acceleration control is mainly used in high-frequency. As a result, not only guarantees the control stability, but also improves the high-frequency performance of electro-hydraulic vibration system and reduces the distortion of acceleration waveform.

The above researches indicate that the current research on vibration waveform of EHVE is based on the traditional servo-valve to improve the vibration waveform control accuracy and reduce the waveform distortion by designing and optimizing the complex control algorithms. But due to the characteristics of servo-valve itself, the vibration frequency cannot make a breakthrough when the vibration waveform has higher requirements. Meanwhile, considering the influence of system nonlinearity, existing a deviation between the electro-hydraulic vibration response signal and input desired signal. Therefore, to reduce the vibration waveform distortion and improve the vibration waveform control accuracy by above-mentioned methods have certain limitations. While the rotary-valve controlled EHVE changes the flow area of the valve port by rotating the spool at a certain speed to generate the vibration waveforms with adjustable frequency and amplitude. Compared with the vibration waveforms of servo-valve controlled EHVE, the waveform distortion of rotary-valve controlled EHVE is relatively small, and it is easy to realize high-frequency excitation, so it has a broader application prospect $[56,57]$. So far, many scholars have done a lot of research on the vibration waveforms of rotaryvalve controlled EHVE. Such as Ruan et al. [58] designed a 2D-valve controlled EHVE and studied the vibration waveforms under different working frequencies. Li et al. $[59,60]$ made the theoretical analysis and experimental research on resonance waveform and vibration waveform of 2D-valve controlled EHVE in the whole frequency bandwidth. Compared with the working frequency of traditional EHVE, the new high-frequency EHVE can be used for vibration tests from low-frequency to highfrequency, and the upper limit working frequency can reach $1000 \mathrm{~Hz}$. Furthermore, Ren et al. [61] studied the theoretical and experimental vibration waveforms under typical input waveforms, obtained the analytical solutions of vibration waveforms, and derived the mathematical expression of harmonics. Meanwhile, in order to realize the accurate control of the offset of hydraulic cylinder piston vibration center position, a new scheme that parallel mechanism consisted of $2 \mathrm{D}$-valve and 
electro-hydraulic digital valve is proposed by Ren et al. [62], and the vibration fatigue tests are carried out in the frequency range of $5-200 \mathrm{~Hz}$. The results show that the parallel mechanism can not only improve the frequency response, but also realize the separate control of vibration frequency and amplitude of EHVE. Moreover, it can realize independent and accurate control of the offset of hydraulic cylinder piston vibration center position. Shao et al. [63] applied the DSP technology to the construction of control system of high-frequency EHVE to realize $2-\mathrm{DOF}$ control of $2 \mathrm{D}$-valve. The acquisition signal is processed by digital filtering, which can improve the control accuracy of EHVE. And the tracking control under nonlinear distortion conditions can realize by the control algorithm while the motor out-of-step and speed mutation can be eliminated.

Besides, Han et al. [34, 64, 65] studied the influence of working frequency on saturation degree of vibration waveform and the influence of the number of spool grooves on fluctuation degree of vibration waveform. At present, the vibration waveforms of rotary-valve controlled EHVE are usually studied based on rectangular valve port, few research work have been done on the influence of different valve port shapes on vibration waveforms. Therefore, according to the previous design, Wang et al. [66] designed a kind of rotary-valve controlled EHVE, and respectively established the flow area models under triangular, semi-circular and rectangular valve port. Wang et al. [67] qualitatively and quantitatively studied the waveform quality of theoretical and experimental vibration waveforms under different oil supply pressures and working frequencies. The results show that the waveform quality is mainly affected by the third harmonic resonance. The waveform distortion of output sinusoidal wave is less than $5 \%$ when the vibration frequency is higher than $70 \mathrm{~Hz}$, and in this frequency range, the influence of oil supply pressure on waveform distortion is extremely small. Therefore, in this vibration frequency, the waveform amplitude can be adjusted by changing the oil supply pressure with the waveform quality is almost unaffected. Liu et al. [68] studied the influence of different valve port structure parameters on the regular wave and obtained the static and dynamic characteristics under different valve port shapes with singlestage rotary-valve controlled EHVE.

\subsection{Progress of Electro-hydraulic Vibration Controller}

As a key component of the whole vibration testing system, the vibration controller has a fundamental influence on the final effect of vibration tests. In the early, the research of electro-hydraulic vibration control system mainly focused on the development of a single-axis electro-hydraulic vibration controller, but gradually,
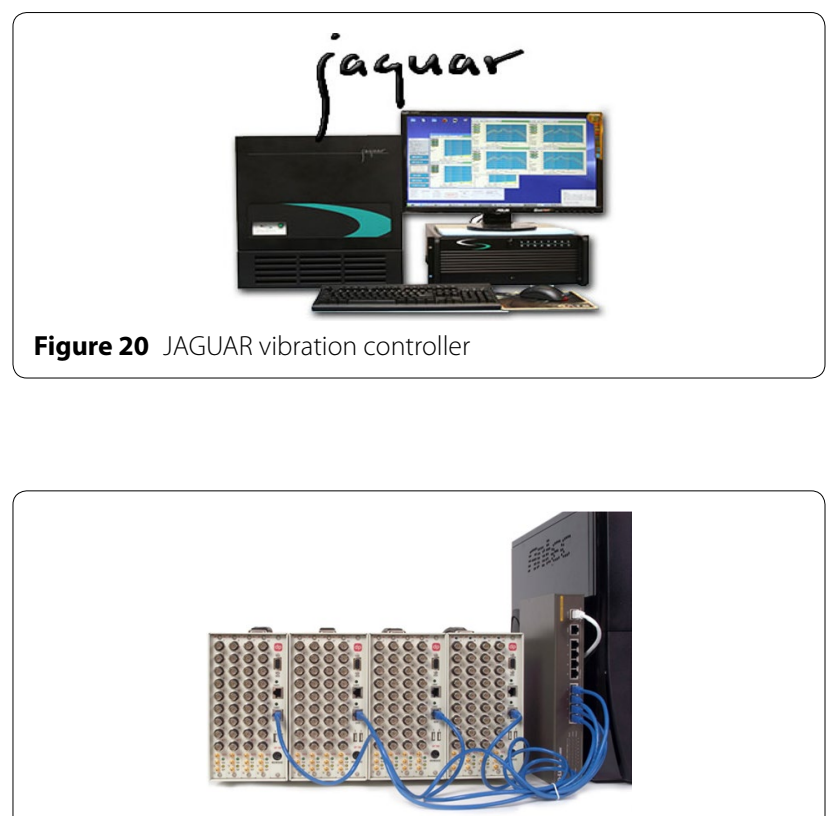

Figure 21 SIGNALSTAR vibration controller

people realized that the multi-axis vibration tests can simulate the actual dynamic environment more accurate and expose the defects and hidden dangers of large and complex structures which are not easily found under single-axis excitation mode. Therefore, several overseas vibration testing and control manufacturers began to pay attention to the development of a multi-axis electro-hydraulic vibration controller. The real-time iterative control technology of vibration controller is the key technology affecting the performance of EHVE. At present, this key technology is mainly monopolized by STI company, WYLE laboratory, MTS company, Data Physics company, Spectral Dynamic company and LMS company [69]. Among them, the JAGUAR electro-hydraulic vibration controller developed by Spectral Dynamics company, as shown in Figure 20 [70], has a complete set of closedloop vibration control application software. It has 98 control channels and more than 500 response channels while the sampling frequency over $25 \mathrm{kHz}$. The unique self-adaption control technology ensures high-accuracy control and safety, while has a comprehensive signal analysis function. The SIGNALSTAR MATRIX DP850 electro-hydraulic vibration controller developed by Data Physics company [71], as shown in Figure 21. It not only provides the vibration control of multi EHST, but also supports the multi-channel vibration control of single EHST. It is considered to be one of the most advanced real-time iterative vibration control systems in the industry. 


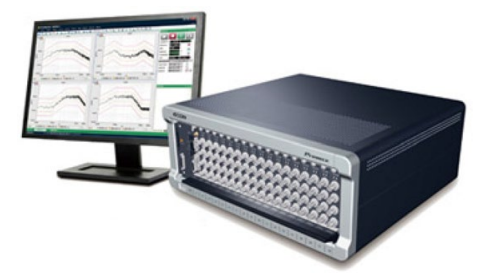

Figure 22 VT series vibration controller

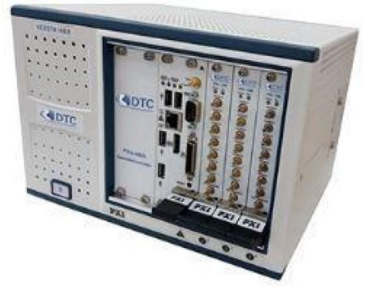

Figure $\mathbf{2 3}$ VESSTA series vibration controller

So far, great progress has been made in the vibration controller in China, although there still has gaps with overseas. Domestic companies engaged in vibration controller research and development are represented by ECON and DynaTronic. As shown in Figure 22 [72], the VT series multi-input and multi-output (MIMO) real-time vibration controller based on multi-DSP parallel processing technology, jointly developed by Zhejiang University and ECON company, can carry out a series of relevant vibration environment tests, such as multi-axis random, sinusoidal sweep and fixed frequency, sinusoidal plus random, vibration shock, time-domain replication, seismic simulation, etc. The controller has the advantage of real-time and high-efficiency, its main frequency of DSP is up to $350 \mathrm{MHz}$, and can respond to any slight change of parameters of vibration environment testing system in time to ensure the stability and high-accuracy of vibration control. As shown in Figure 23 [73], the VESSTA series MIMO vibration controller based on PXIe bus and multi-DSP board structure are developed by DynaTronic company. Through the combination of different number of data acquisition board and output board, it can easily meet the needs of flexible collocation of channel size. Its one-way transmission speeds up to $250 \mathrm{Mb} / \mathrm{s}$, and can realize the multi-channel parallel acquisition and real-time closed-loop control by distributed acquisition and centralized processing. Meanwhile, other domestic universities and institutions have also done a lot of research on vibration controller, such as Beihang University, Nanjing University of Aeronautics and Astronautics, National University of Defense Technology,
Aerospace Ministry No. 702 Institute, Aerospace Ministry No. 623 Institute, Xi'an Jiaotong University, etc.

In addition to the large enterprises and institutions above-mentioned, domestic and overseas scholars have done a lot of research on vibration controller as well. Such as overseas scholar Plummer [74] proposed a new model-based motion control method for multi-axis EHST. Compared with the traditional proportional controller, it has a better performance. For example, the horizontal acceleration frequency bandwidth is nearly six times higher than that of the traditional proportional controller and the hydraulic resonance frequency is also many times higher. Thenozhi et al. [75] effectively combined the offset elimination and high-pass filtering technology to solve the common problems in the numerical integration of acceleration signals. While the integration accuracy is improved compared with other numerical integrators. Nakata $[44,76]$ proposed a control method called acceleration trajectory tracking control (ATTC) and a multi-purpose single-axis seismic simulation controller, which can improve the acceleration control performance of seismic simulation controller and increase the flexibility.

Domestic scholar Shen et al. [77] proposed a method of combining self-adaption controller and off-line compensator to improve the acceleration frequency bandwidth and tracking accuracy of 6-DOF EHST. Compared with the traditional three-variable controller and selfadaption controller, the acceleration tracking control performance, including the convergence speed and acceleration tracking accuracy of LMS algorithm, is improved. Yan et al. [78] designed a multi-dimensional waveform reproducing controller by studying the multidimensional waveform reproducing control algorithm, and realized the six-dimensional waveform reproducing control simulation with a three-axis 6-DOF EHST prototype. The controller has been successfully applied to a low-frequency horizontal seismic simulation EHST and a high-frequency seismic simulation electro-hydraulic vibration system, and their effect of waveform reproducing is satisfactory. $\mathrm{Xu}$ [79] analyzed and studied the random vibration power spectrum reproducing control algorithm in the vibration testing control system, and discussed the method of designing a vibration controller with high-performance DSP chip. The experiment showed that the algorithm is better than the traditional algorithm in the practical application of engineering and the designed vibration controller is actually available. In order to overcome the shortcomings of the analog servo controller, Shu et al. [80] designed an electro-hydraulic digital servo controller based on FPGA and classical PID control algorithm. The designed controller has good static and dynamic response performance and high 
performance-price ratio compared with the analog controller. To realize high-frequency and high-magnitude earthquake simulation vibration tests on the centrifuge, Deng et al. [81] designed a set of digital control system for seismic waveform replication, and reproduced the time-domain seismic waveform on the centrifugal EHST which can meet the testing requirements. While the effect and accuracy of vibration control are satisfied with the technical requirements for system development.

Moreover, Feng et al. [82] proposed a control strategy based on predictive function control algorithm, and designed a predictive function controller for electro-hydraulic vibration control system. The proposed strategy for the controller has strong robustness and anti-interference ability, which can effectively improve the accuracy of dynamic tracking of an electro-hydraulic vibration control system. Luan et al. [83] systematically studied the control strategy of 3-stage servo-valve controlled EHST, designed an integrated controller for high-flow EHST, which can simultaneously realize the servo control and vibration control of EHST. Through the integrated controller, the waveform replication tests of 3-stage servo-valve controlled EHST under different time-history and frequency bandwidth are carried out. The results show that the controller for EHST has a good waveform control ability and can realize high-accuracy waveform replication of EHST. Ma et al. [84] analyzed the three-axis vibration testing system, studied the multiinput and multi-output power spectrum reproducing control algorithm, and carried out the vibration tests with the three-axis EHST and multi-input and multioutput vibration controller integrated with the algorithm. The results show that the HV frequency response function estimation modified iterative control algorithm has good power spectrum reproducing accuracy and engineering practicability.

\section{Problems and Prospects}

Due to the higher requirements for large-scale vibration environment simulation tests and working frequency of electro-hydraulic vibration equipment, the existing electro-hydraulic vibration control technology has the following problems.

(1) The vibration frequency of rotary-valve controlled electro-hydraulic vibration equipment is easier to improve than that of the servo-valve controlled electro-hydraulic vibration equipment. But due to the structural symmetry of rotary-valve, cannot introduce an offset signal to realize the offset control of vibration center position just like the servovalve controlled electro-hydraulic vibration equipment. In the absence of offset control, on the one hand, it cannot satisfy some offset vibration conditions. On the other hand, the vibration center position cannot be corrected in time when away from the balance position of the piston.

(2) From the above published, many research achievements have been obtained on output vibration waveform distortion and control accuracy of electro-hydraulic vibration equipment. However, the output vibration waveform distortion control and stability control still have a lot of room for improvement under high-frequency excitation conditions.

(3) The inlet and outlet valve port throttle area of vibration control valves (including servo-valve and rotary-valve) of high-frequency electro-hydraulic vibration equipment is always adjusted by a spool, which cannot realize the independent control of the load port. Therefore, the change of valve port flow area is limited to a certain extent, and it is not easy to control the vibration waveforms flexibly under complex working conditions.

(4) Some domestic manufacturers have developed a series of vibration controllers with good performance, such as VT series and VESSTA series, but there still have gaps in multi-channel vibration control compared with overseas, and most of them are designed for electro-dynamic shaking table. The high-end vibration controllers especially used in electro-hydraulic shaking tables are not perfect. Few mature and reliable products have been put into practical application, still in theoretical research.

Aiming at the problems of waveform distortion and offset control of existing electro-hydraulic vibration equipment under high-frequency vibration conditions, a new method of twin-valve independently controlled electro-hydraulic vibration is proposed to meet the requirements of waveform control and vibration control. (patent number: CN108571496A and CN108397448A) As shown in Figures 24, 25 and 26. The characteristics of twin-valve independently controlled electro-hydraulic vibration system are based on dislocation combination of two rotary- valve spools. The control of vibration frequency is realized by adjusting the rotary speed of spool which is controlled by servo motor connected to the gear. The high-frequency excitation is realized by optimizing the arrangement and transmission ratio of the gear and the matching mode of valve sleeve window and spool shoulder groove. The axial displacement of each spool is controlled by a linear motor of two rotary valves, and the waveform amplitude and offset in the electro-hydraulic vibration system can be independently controlled. So 


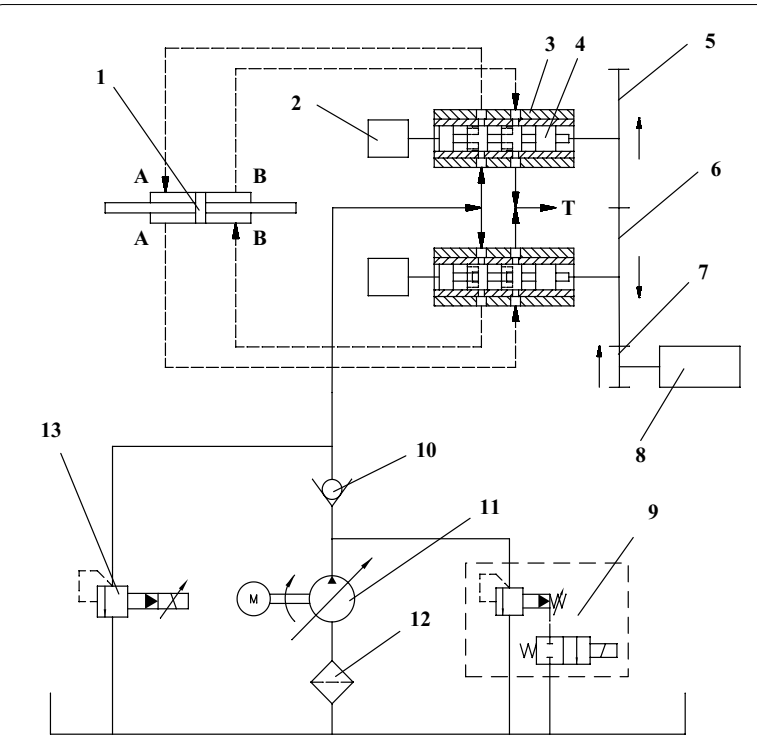

Figure 24 New method of twin-valve independently controlled high-frequency electro-hydraulic vibration. 1. Vibration hydraulic cylinder; 2. Linear motor; 3. Valve body; 4. Spool; 5. Large gear 1; 6 . Large gear 2; 7. Small gear; 8 . Servo motor; 9. Pilot electromagnetic relief valve; 10 . One-way valve; 11 . Constant pressure proportional variable pump; 12. Filter; 13. Pilot proportional relief valve

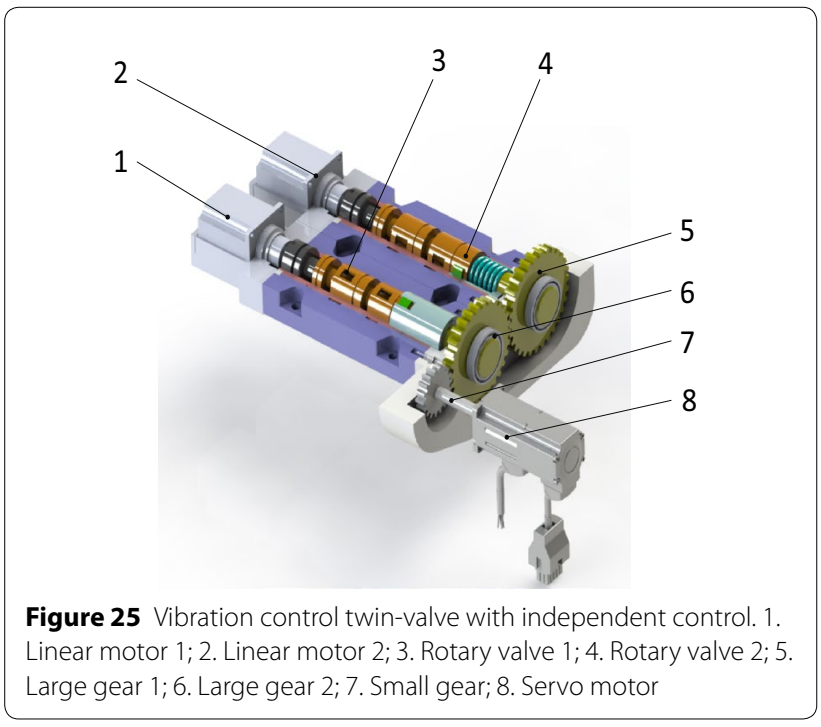

that the electro-hydraulic vibration system can simultaneously realize the control of waveform frequency, waveform amplitude and vibration center offset. Thus, the matching compensation control of vibration waveform under high-frequency vibration conditions can be realized, the accuracy of vibration waveform and technical level of vibration environment simulation tests can be improved.

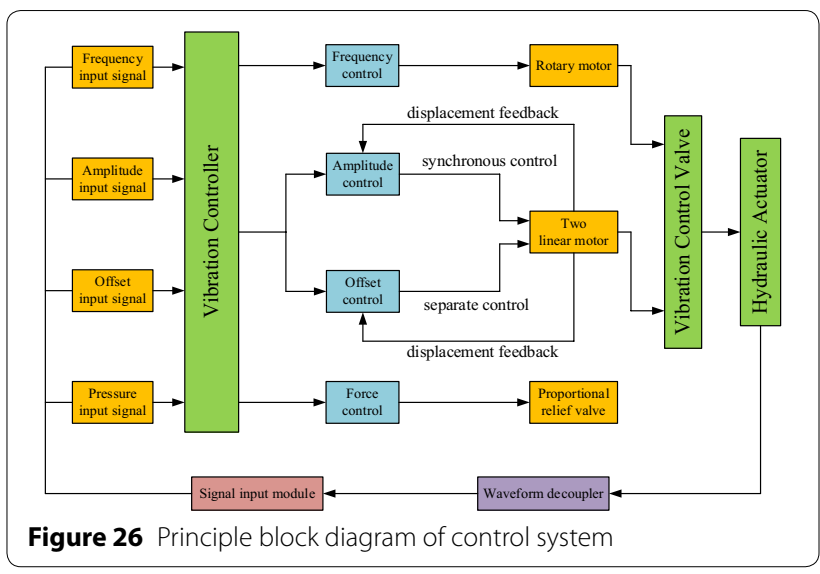

Based on the new method and structure above-mentioned, considering the requirements of accurate simulation of high-frequency vibration waveform in large-scale vibration environment simulation tests. Studying the mapping relationships between the high-frequency vibration waveform and the shape and structure parameters of valve port when the two spools synchronous rotating in opposite directions. Revealing the influence of fluid physical properties, rotational speed fluctuation, structural combination form and valve port size error on output vibration waveform. Analyzing the inherent amplitude and phase frequency characteristics of electro-hydraulic vibration system with different structure and control parameters. Revealing the dynamic response law of electro-hydraulic vibration system under high-frequency vibration conditions. Proposing a new method of distributed control for high-frequency electro-hydraulic vibration system. Expecting to break through the limitations of current electro-hydraulic vibration technology in bandwidth and waveform distortion, and provide technical support for the development of high-frequency and high-power electro-hydraulic vibration system.

\section{Conclusions}

The high-frequency electro-hydraulic vibration control technology is widely used in large-scale projects, on the one hand, it can carry out high cycle fatigue tests in much less time to shorten the development cycle of products, on the other hand, it determines the level of product performance and structure optimization. Meanwhile, it is not only an important indicator of the level of national industrial technology development, but also indispensable basic research. With the development of national high-end equipment manufacturing industry, the higher requirements on replication accuracy, distortion and stability of vibration waveform under high-frequency vibration conditions are put forward. In order to reduce the 
import of overseas high-end electro-hydraulic vibration equipment, it is urgent to carry out research on domestic high-frequency electro-hydraulic vibration equipment and corresponding high-frequency electro-hydraulic vibration control technology to improve the control accuracy and stability of electro-hydraulic vibration equipment under high-frequency vibration conditions. In a word, it is of great significance to improve the overall technical level of large-scale vibration environment simulation tests of China and international competitiveness of national equipment manufacturing industry and products.

\section{Authors' Contributions}

GG determined the subject discussed and wrote an outline; YL and TW collected and wrote the manuscript; RG assisted with revision and translation. All authors read and approved the final manuscript.

\section{Authors' Information}

Yi Liu, born in 1985, is currently an associate professor at Ningbo Institute of Technology, Zhejiang University, China. He received his PhD degree from Zhejiang University, China, in 2013. His research interests include electro-hydraulic vibration control and wave simulation control.

Tao Wang, born in 1994, is currently a master candidate at Anhui University of Science \& Technology and Ningbo Institute of Technology, Zhejiang University, China. His research interests include electro-hydraulic vibration control.

Guofang Gong, born in 1963, is currently a professor and a PhD candidate supervisor at State Key Laboratory of Fluid Power Transmission and Control, Zhejiang University, China. His research interests include hydraulic transmission and control.

Rujun Gao, born in 1994, is currently a master candidate at Zhejiang University, China.

\section{Competing interests}

The authors declare that they have no competing interests.

\section{Funding}

Supported by National Natural Science Foundation of China. (Grant Nos. $51605431,51675472)$

\footnotetext{
Author Details

${ }^{1}$ Ningbo Institute of Technology, Zhejiang University, Ningbo 315100, China. 2 State Key Laboratory of Fluid Power Transmission and Control, Zhejiang University, Hangzhou 310027, China. ${ }^{3}$ Ningbo Research Institute, Zhejiang University, Ningbo 315100, China
}

Received: 14 March 2019 Revised: 20 August 2019 Accepted: 25 October 2019

Published online: 27 November 2019

\section{References}

[1] ZW Cheng, H J Yu. Existing state and development of vibration control technology. Journal of Vibration and Shock, 2009, 28(3): 73-77. (in Chinese)

[2] X J Li, F F Li, J B Ji, et al. A new control technology of shaking table based on the jerk. Advanced Engineering Sciences, 2018(3): 64-72. (in Chinese)

[3] Y G Xin, B H Dou, Y Pei, et al. Application of high frequency electrohydraulic vibration system. Machine Tool \& Hydraulics, 2015, 43(13): 106107. (in Chinese)

[4] W Wang. Research on the technology of impact vibration based on fourway rotary valve. Zhejiang University, 2016. (in Chinese)

[5] MTS Systems Corporation. $1000 \mathrm{~Hz}$ high-cycle fatigue test system, 2015. https://www.mts.com/cs/groups/public/documents/library/ dev_002041.pdf.
[6] MTS Systems Corporation. Servovalves, 2015. https://www.mts.com/cs/ groups/public/documents/library/mts_006302.pdf.

[7] MOOG Inc. Overview servo valve range, 2019. https://www.moog.it/ content/dam/sites/italy/pdf/servovalvole/Moog-Servo-Valve-Overv iew-en.pdf.

[8] MOOG Inc. D633/D634 series servovalves, 2019. https://www.moog. com/literature/ICD/Moog-Valves-D633_D634-Catalog-en.pdf.

[9] MOOG Inc. D765 series servovalves, 2019. https://www.mylesgroup companies.com/moog_pdfs/CDL6563-F\%20D765\%20Series.pdf.

[10] MOOG Inc. 760 Series servovalves, 2019. https://www.moog.com/liter ature/ICD/760seriesvalves.pdf.

[11] MOOG Inc. 79 Series servovalves, 2019. https://www.moog.com/liter ature/ICD/Moog-Valves-79-Series-Catalog-en.pdf.

[12] TEAM Corporation. MANTIS brochure, 2014. http://www.teamcorpor ation.com/images/brochures/Mantis.pdf.

[13] TEAM Corporation. The CUBE brochure, 2016. http://www.teamcorpor ation.com/images/brochures/Team_Cube_8.5_x_11.pdf.

[14] TEAM Corporation. Engine simulator brochure, 2014. http://www. teamcorporation.com/images/brochures/Engine-Simulation-Syste ms.pdf.

[15] G Shen, Y Tang, X Li. Parallel redundantly actuated electro-hydraulic shaking table control system. Beijing: Science Press, 2016: 3-21. (in Chinese)

[16] SERVOTEST Testing Systems Ltd. Vibration MAST systems, 2013. http:// www.servotestsystems.com/images/PDFs/ST_brochures/08_Vibra tion_MAST_tables.pdf.

[17] SERVOTEST Testing Systems Ltd. Company introduction, 2018. http:// www.servotestsystems.com/images/PDFs/ST_brochures/Servotest_ Company_Introduction.pdf.

[18] IMV Corporation. Dynamic simulation system full lineup catalogue, 2016. http://www.imv-china.cn/catalog_dl/pdf/dss_catalogue.pdf.

[19] M Nakashima, T Nagae, R Enokida, et al. Experiences, accomplishments, lessons, and challenges of E-defense-Tests using world's largest shaking table. Japan Architectural Review, 2018, 1(1): 4-17.

[20] T L Zhang. Design and servo control study of single-axis high-frequency electro-hydraulic shaking table. Zhejiang University, 2018. (in Chinese)

[21] K Wan, P Wang, D Y Zhu. Present situation and the development in electro-hydraulic vibration control system. Electronic Instrumentation Customers, 2012, 19(4): 1-5. (in Chinese)

[22] J W Han, L P Zhang. The development and control technology of multiDOF shaker. Chinese Hydraulics \& Pneumatics, 2014(1): 1-6. (in Chinese)

[23] C J Li. Research on key issues in design of large earthquake simulation shaking table foundation. Southeast University, 2016. (in Chinese)

[24] M Goldfarb, E J Barth, K B Fite, et al. High bandwidth rotary servo valves: US, 7322375B2. 2008-01-29. https://patents.google.com/paten t/US7322375B2/en

[25] P G V Kerckhove, P Ma. Rotary-actuated electro-hydraulic valve: US, 7735517B2. 2010-06-15. https://patents.google.com/patent/US773 $5517 B 2 /$ en.

[26] M Ruggeri, P Marani. A new high performance roto-translating valve for fault tolerant applications (No. 2014-01-2403). SAE Technical Paper, 2014.

[27] W Yang. Research on fault tolerance principle and error correction method for fluid drive and control application system. University of Electronic Science and Technology of China, 2012. (in Chinese)

[28] PY Li, TR Chase. Pulse width modulated fluidic valve: US, $8286939 B 2$. 2012-10-16. https://patents.google.com/patent/US8286939B2/en.

[29] M Wang. CFD analysis, sensing and control of a rotary pulse width modulating valve to enable a virtually variable displacement pump. USA: University of Minnesota, 2017

[30] M Pan, N Johnston, J Robertson, et al. Experimental investigation of a switched inertance hydraulic system with a high-speed rotary valve. Journal of Dynamic Systems Measurement \& Control, 2015, 137(12): 121003.

[31] J Ruan, S Li, X Pei, et al. Electrohydraulic vibration exciter controlled by 2D valve. Journal of Mechanical Engineering, 2009, 45(11): 131-138. (in Chinese)

[32] M J Lu. The research of the controller for the single-axis high frequency electro-hydraulic shaking table. Zhejiang University of Technology, 2012. (in Chinese)

[33] G F Gong, D Han, Y Liu, et al. An electro-hydraulic exciter: CN, 102734279B. 2014-12-10. http://pro.soopat.com/Chinese/Paten $\mathrm{t}$ ?SQH $=201210218096 \& \mid \mathrm{x}=\mathrm{FMSQ}$. (in Chinese) 
[34] D Han, G F Gong, Y Liu, et al. New electro-hydraulic exciter based on different spools. Journal of Zhejiang University (Engineering Science), 2014 48(5): 757-763. (in Chinese)

[35] J F Li, Z B Xu, J L Wang. Magneto-strictive driven electro-hydraulic exciter: CN, 103075395A. 2013-05-01. http://pro.soopat.com/Chinese/Paten $\mathrm{t} ? \mathrm{SQH}=201310037249 \& \mathrm{l}=\mathrm{FMZL}$. (in Chinese)

[36] G Toet. Device for compacting a granular mass such as concrete cement: US, 9211663B2. 2015-12-15. https://patents.google.com/patent/US921 1663B2/en.

[37] A Kleibl, C Heichel. Vibration exciter: US, 20140305234A1. 2014-10-16. https://patents.google.com/patent/US20140305234A1/en.

[38] K Kobayashi, I Kono, T Kondo, et al. Vibration exciter: US, 20180031445 A1. 2018-02-01. https://patents.google.com/patent/US20180031445A1/en.

[39] D D Hou, D Cheng, L P Qin, et al. Electro-hydraulic acceleration control strategy based on three states controller. Chinese Hydraulics \& Pneumatics, 2018(5): 47-53. (in Chinese)

[40] B Liu, J Zhang, X C Dou, et al. Research on three state controller policy of hydraulic vibration table. Machine Tool \& Hydraulics, 2014, 42(19): 136-140. (in Chinese)

[41] P Righettini, R Strada, S Valilou, et al. Nonlinear model of a servo-hydraulic shaking table with dynamic model of effective bulk modulus. Mechanical Systems \& Signal Processing, 2018, 110: 248-259.

[42] W Kim, D Won, D Shin, et al. Output feedback nonlinear control for electro-hydraulic systems. Mechatronics, 2012, 22(6): 766-777.

[43] S K Wang, J Z Wang, W Xie, et al. Development of hydraulically driven shaking table for damping experiments on shock absorbers. Mechatronics, 2014, 24(8): 1132-1143.

[44] N Nakata. Acceleration trajectory tracking control for earthquake simulators. Engineering Structures, 2010, 32(8): 2229-2236.

[45] A Klimchik, D Chablat, A Pashkevich. Stiffness modeling for perfect and non-perfect parallel manipulators under internal and external loadings. Mechanism \& Machine Theory, 2014, 79(79): 1-28.

[46] W Wei, Z D Yang, J W Han. Decoupling control of hyper-redundant shaking table based on dynamic coupling model. Journal of South China University of Technology (Natural Science Edition), 2014, 42(4): 124-130. (in Chinese)

[47] G Shen, Z C Zhu, L Zhang, et al. Adaptive feed-forward compensation for hybrid control with acceleration time waveform replication on electro-hydraulic shaking table. Control Engineering Practice, 2013, 21(8): 1128-1142.

[48] J J Yao, Z S Wan, Y Fu. Acceleration harmonic estimation in a hydraulic shaking table using water cycle algorithm. Shock and Vibration, 2018, 2018(6): 1-12.

[49] S D Bruyne, HV D Auweraer, B Peeters, et al. Model based control of a multi-axis hydraulic shaker using experimental modal analysis. IFAC Proceedings Volumes, 2012, 45(16): 524-528.

[50] K P S Rana. Fuzzy control of an electrodynamic shaker for automotive and aerospace vibration testing. Expert Systems with Applications, 2011, 38(9): 11335-11346.

[51] M Stehman, N Nakata. Direct acceleration feedback control of shake tables with force stabilization. Journal of Earthquake Engineering, 2013, 17(5): 736-749.

[52] G Shen, Z C Zhu, X Li, et al. Experimental evaluation of acceleration waveform replication on electrohydraulic shaking tables: A review. International Journal of Advanced Robotic Systems, 2016, 13(5): 1-25.

[53] L Zhang, D Cong, Z Yang, et al. Optimal design and hybrid control for the electro-hydraulic dual-shaking table system. Applied Sciences, 2016, 6(8): 220.

[54] Y Tang, G Shen, Z C Zhu, et al. Time waveform replication for electrohydraulic shaking table incorporating off-line iterative learning control and modified internal model control. Proceedings of the Institution of Mechanical Engineers Part I Journal of Systems \& Control Engineering, 2014, 228(9): 722-733.

[55] X Yan, Y Wang, B L Niu, et al. A displacement and acceleration hybrid control technology to improve high-frequency characteristics in hydraulic vibration system. Machine Tool \& Hydraulics, 2015, 43(20): 84-87. (in (hinese)

[56] Y Liu, G F Gong, HY Yang, et al. Mechanism of electro-hydraulic exciter for new tamping device. Journal of Central South University, 2014, 21(2): 511-520.
[57] Y Liu, G F Gong, C Q Min. Present status and prospect of tamping device exciting technology. Journal of Mechanical Engineering, 2013, 49(16): 138145. (in Chinese)

[58] J Ruan, RT Burton. An electrohydraulic vibration exciter using a twodimensional valve. Journal of Systems and Control Engineering, 2009, 223(2): 135-147.

[59] W R Li, J Ruan, Y Ren. Vibration waveform research on electro-hydraulic exciter of differential cylinder controlled by 2D valve. Transactions of the Chinese Society for Agricultural Machinery, 2013, 44(10): 266-271. (in Chinese)

[60] W R Li, H S Hu, J Z Wu. Research on the full-band vibration waveform of high frequency electric hydraulic vibrostand. Value Engineering, 2016, 35(4): 131-133. (in Chinese)

[61] Y Ren, J Ruan. Theoretical and experimental investigations of vibration waveforms excited by an electro-hydraulic type exciter for fatigue with a two-dimensional rotary valve. Mechatronics, 2016, 33: 161-172.

[62] Y Ren, J Ruan, W A Jia. Bias control strategy for electro-hydraulic vibration exciter with two-dimensional valve. Journal of Xi'an Jiaotong University, 2010, 44(9): 82-86. (in Chinese)

[63] H Q Shao, J Ruan, S Li, et al. High-frequency electro-hydraulic vibration system controller based on DSP. Journal of Mechanical \& Electrical Engineering, 2012, 29(1): 66-69. (in Chinese)

[64] D Han, G F Gong, Y Liu, et al. Waveform saturation of electro-hydraulic excitation technology. Transactions of the Chinese Society for Agricultural Machinery, 2014, 45(2): 334-339. (in Chinese)

[65] D Han, G F Gong, H Y Yang, et al. Waveforms analysis and optimization of new electro-hydraulic excitation technology. Journal of Central South University, 2014, 21(8): 3098-3106.

[66] H Wang, G F Gong, H B Zhou, et al. Research on vibration waveform of electro-hydraulic exciter with rotary valve based on different valve port shapes. Journal of Mechanical Engineering, 2015, 51(24): 146-152. (in (hinese)

[67] H Wang, G F Gong, H B Zhou, et al. A rotary valve controlled electrohydraulic vibration exciter. Proceedings of the Institution of Mechanical Engineers, Part C: Journal of Mechanical Engineering Science, 2015, 230(19): 3397-3407.

[68] Y Liu, S K Cheng, G F Gong. Structure characteristics of valve port in the rotation-spool-type electro-hydraulic vibrator. Journal of Vibration \& Control, 2015, 23(13): 2179-2189.

[69] Z D Yang. Research on control technologies of simulation of vibration environment using hydraulic vibration table. Harbin Institute of Technology, 2009. (in Chinese)

[70] Spectral Dynamics, Inc. JAGUAR shaker control and analysis system datasheet, 2017. http://www.spectraldynamics.com/images/docs/Jaguar/ Brochures/DataSheet_jagHWds_012808.pdf.

[71] Data Physics Corporation. SIGNALSTAR family brochure, 2017. http://cdn2. hubspot.net/hubfs/409629/eBooks/Data_Physics/SignalStar_Controller s-Family_Brochure-Data_Physics_Corporation.pdf.

[72] ECON Technologies. MIMO vibration controller, 2019. http://www. econ-group.com.cn/ch/productView.asp?id=78\&num $=1 \& \mathrm{id} 2=101$. (in Chinese)

[73] DynaTronic Corporation. MIMO vibration control system, 2019. http://www dtc-solutions.cn/product/7162.html. (in Chinese)

[74] A R Plummer. Model-based motion control for multi-axis servo-hydraulic shaking tables. Control Engineering Practice, 2016, 53: 109-122.

[75] S Thenozhi, W Yu, R Garrido. A novel numerical integrator for velocity and position estimation. Transactions of the Institute of Measurement \& Control, 2013, 35(6): 824-833.

[76] N Nakata. A multi-purpose earthquake simulator and a flexible development platform for actuator controller design. Journal of Vibration \& Control, 2012, 18(18): 1552-1560.

[77] G Shen, X Li, Z C Zhu, et al. Acceleration tracking control combining adaptive control and off-line compensators for six-degree-of-freedom electro-hydraulic shaking tables. ISA Transactions, 2017, 70: 322.

[78] X Yan, B L Niu, Q S Li. Multi-dimensional waveform reproduction contro system design and development. Journal of Vibration and Shock, 2007 26(9): 162-164. (in Chinese)

[79] J C Xu. Research and implementation of random vibration controller based on DSP. Yangzhou University, 2015. (in Chinese) 
[80] Y Shu, Q Song, Q S Li, et al. Design of digital servo controller for electrohydraulic shaking table based on FPGA. Machine Tool \& Hydraulics, 2013, 41(15): 148-150. (in Chinese)

[81] T Deng, XYan, et al. Application of embedded controller in vibration test of earthquake-simulation on centrifuge. Computer Measurement \& Control, 2016, 24(3): 127-128. (in Chinese)

[82] X G Feng, J Y Zhang, P M Xu, et al. PFC optimization control strategy research on hydraulic vibration servo system. Journal of Vibration Engineering, 2017, 30(3): 389-396. (in Chinese)
[83] Q L Luan, Z W Cheng, H N He. Control strategy for a hydraulic shaker controlled with a 3-stage electro-hydraulic servo valve. Journal of Vibration and Shock, 2014, 33(24): 138-143. (in Chinese)

[84] X B Ma, Z W Cheng, Y G Zhao, et al. Three-axis vibration control based on drive spectrum modified iterative control algorithm. Journal of Vibration and Shock, 2018, 37(3): 85-90. (in Chinese)

\section{Submit your manuscript to a SpringerOpen ${ }^{\circ}$ journal and benefit from:}

- Convenient online submission

- Rigorous peer review

- Open access: articles freely available online

- High visibility within the field

- Retaining the copyright to your article

Submit your next manuscript at springeropen.com 